\title{
Adverse incidents resulting in exposure to body fluids at a UK dental teaching hospital over a 6-year period
}

This article was published in the following Dove Press journal:

Infection and Drug Resistance

24 October 2012

Number of times this article has been viewed

\author{
A Hughes' \\ L Davies' \\ R Hale' \\ JE Gallagher ${ }^{2}$ \\ 'Kings College Hospital NHS \\ Foundation Trust, ${ }^{2}$ King's College \\ London Dental Institute, London, \\ United Kingdom
}

Correspondence: Jennifer E Gallagher King's College London Dental Institute, Denmark Hill Campus, Caldecot Road, London SE5 9RW, United Kingdom

Tel +44 20399 348I

Email jenny.gallagher@kcl.ac.uk
Background: The safety and protection of patients and health care workers is of paramount importance in dentistry, and this includes students in training who provide clinical care. Given the nature of dental care, adverse incidents can and do occur, exposing health care workers to body fluids and putting them at risk of infection, including contracting a blood-borne virus. The aim of this research was to analyze trends in the volume, rate, nature, management, and outcome of adverse incidents reported at one dental teaching hospital from 2005 to 2010.

Methods: Descriptive analysis of trends in the volume, rate, nature, management, and outcome of adverse incidents reported at one dental teaching hospital over a six-year period was undertaken in relation to the level of outpatient and day surgery activity.

Results: In total, 287 incidents were reported over a six-year period, which amounted to $0.039 \%$ of outpatient or day surgery appointments. Nearly three quarters of all the incidents $(n=208,72 \%)$ took place during treatment or whilst clearing away after the appointment. The most frequent incidents were associated with administration of local anesthetic $(n=63,22 \%)$, followed by burs used in dental hand pieces $(n=51,18 \%)$.

Conclusion: This research confirms that adverse incidents are a feature of dental hospitals and reports the common sources. The importance of accurate and consistent reporting of data to ensure that these issues are monitored to inform action and reduce risks to staff, students, and patients are highlighted.

Keywords: risk management, blood-borne virus, dental hospital, body fluids exposure, adverse event reporting

\section{Introduction}

High quality infection control is of great importance in dentistry for the safety and protection of both patients and health care workers, including those in training. Adherence to hospital guidelines, taking universal precautions, and ensuring routine use of personal protective equipment is actively promoted, but there is always a risk that an adverse incident can occur, thus exposing the health care worker to body fluids, including blood products, and putting them at risk of infection including contracting a blood-borne virus. It is important that systems are in place to minimize such incidents and to deal with them appropriately when they occur. Recording of incidents is an established process to ensure that the National Health Service (NHS) learns from adverse incidents, which then in turn inform processes to minimize their occurrence in future. ${ }^{1}$

The World Health Organization defines an "adverse incident" as "an injury related to medical management, in contrast with complication of disease. Adverse events may be preventable or non-preventable". ${ }^{2}$ 
Within England, each hospital trust has its own policy in place for acknowledging, reporting, and investigating such incidents. King's College Hospital NHS Trust defines an "adverse incident" as "an unintended event or circumstance which adversely affects patients, staff, visitors or the Trust's assets/reputation or has potential to do so". The trust also has a framework in place to report any "near miss" event as well as a potential "hazard". The policy is revised and updated every three years.

It has been suggested that within the dental environment, compared with many other health care settings, "sharps injuries" are more likely, due to a small operating field, frequent patient movement, and the variety of sharp dental instruments used in everyday practice. ${ }^{3}$

A busy dental teaching hospital with a large patient catchment area where there is a high incidence and prevalence of blood-borne viruses ${ }^{4,5}$ further increases the risk of adverse incidents occurring due to relative operator inexperience, a high turnover of staff, and an exceptionally high intake of patients.

All health care professionals and students carrying out exposure-prone procedures need to have "full health clearance" before commencement of an appointment. They must provide evidence that they are noninfectious for human immunodeficiency virus (HIV, antibody negative), hepatitis $B$ virus (surface antigen negative or, if positive, e-antigen negative with a viral load of $10^{3}$ genome equivalents $/ \mathrm{mL}$ or less) and hepatitis $\mathrm{C}$ virus (antibody negative or, if positive, negative for hepatitis C RNA). ${ }^{4}$

Supporting the above requirement for full health clearance, are the estimated published figures, ie, 85,000 of UK residents are now living with HIV, with up to $25 \%$ being unaware that they are infected with the virus. The risk of seroconversion following a percutaneous injury with a needle or sharp device visibly contaminated with blood has been estimated as 1 in 3 for hepatitis B virus, 1 in 30 for hepatitis $\mathrm{C}$ virus, and 1 in 300 for HIV. These statistics re-enforce and emphasize the need for high quality infection control and the need to prevent the occurrence of adverse incidents. ${ }^{5}$

\section{Immediate management, reporting, and risk assessment}

When an adverse incident occurs at Kings College London, the first priority of those involved is to make the environment safe and treat any injuries caused by the incident. ${ }^{6}$ The incident must be reported as soon as it is safe to do so, and within one working day. Risk management is the responsibility of all staff and students within the trust. Any staff or student involved in, witness to, or made aware of an adverse incident has a duty to report it. If and when an incident occurs, the local manager should be informed at the earliest opportunity. The incident is then required to be documented using the trust's online Datixweb form (http://datix/datix/ live/index.php). Alternatively, if the web is unavailable, a paper form should be completed and submitted to the risk management department. All incidents that have been formally reported at the dental hospital since 2005 have been uploaded onto this standardized trust software, making the collection of data for this research efficient. The seriousness of the incident is determined by assessing the consequence level, with "catastrophic" being the highest and "insignificant" being the lowest. "Likelihood" of a repeat incident is also considered, with "incidents" being graded by risk managers as red, amber, yellow, or green. ${ }^{6}$

Adverse incidents, or near misses, are to be treated and investigated at a level correspondent with their seriousness, and a formal process is put in place whereby the reporter has two working days to confirm with the risk management department, and the relevant divisional manager (head of dental nursing) is ultimately responsible for confirming whether the incident is declared as a "serious adverse incident". 6

\section{Research questions}

This research set out to answer the following questions:

- What are the trends in the reported number and rate of adverse incidents over the last six years?

- What are the trends in the reported number and rate of adverse incidents, within the calendar year?

- Which procedures are most commonly associated with adverse incidents?

- What is the context of reported incidents?

- What is the outcome of reported incidents?

- In light of the findings, what are the recommendations for future action?

The aim of this study was to analyze the trends in the volume, rate, nature, management and outcome of adverse incidents reported at one dental teaching hospital over a 6-year period from 2005 to 2010.

\section{Materials and methods}

Details of all the incidents that occurred at Kings College Dental Hospital from January 2005 until December 2010 were transported into SPSS version 17 (SPSS Inc, Chicago,

IL) for analysis. The data included:

- Incident reference number

- Incident date 
- Grade

- Location

- Category

- Description of incident

- Action taken and

- Investigation, findings, and reporting

- Closing date

Categorization of descriptive data on the incident and investigation was carried out manually by examining the "description" and "action" of each incident in the records. One researcher $(\mathrm{AH})$ reviewed the descriptive data in the field and created a series of categories based on the nature of the incident. All incidents of low frequency were grouped as "other sharps". The findings were discussed and the categories formalized. Where an incident could apply to more than one category, it was recorded in the more dominant category, as determined by two researchers (JG and AH). The categorization of incidents was verified by the dental hospital risk manager (LD).

Data for the volume of outpatient attendances at the hospital each month from January 2005 to December 2010 were obtained from the dental operations manager, along with the number of cases admitted for day surgery. This provides a context for the level of possible exposure-prone procedures, albeit that not all outpatient cases involve such procedures, particularly if there is only a dental examination and no dental probe is used. Reported incidents and the rate of incidents per month were calculated.

\section{Results}

\section{Number of incidents reported}

In total, 287 adverse incidents that resulted in potential exposure of health care workers to body fluids were reported over six calendar years (2005-2010). It can be observed from the results that the volume of reported incidents peaked in 2007 $(\mathrm{n}=61)$, with an increase of nearly $50 \%$ on the previous year. The number of incidents reduced again to 51 in 2008, and reached a plateau at a similar level throughout 2009 and 2010. The average number of outpatients seen at the dental hospital during the study period ranged between 80,000 and 120,000 per year. The number of surgical day case admissions almost doubled between 2005 and 2009, accounting for an average of 9000 admissions per year (range 6-10,000). The overall adverse incident rate for the dental hospital activity (outpatient appointments and day cases) over the 6-year period was 3.9 per 10,000 visits.

There was variation by month within the calendar year, with the average number of incidents reported being highest in October and lowest in August; this trend was most marked during 2007 when activity was highest. Although the rate largely parallels the volume of patients seen at the dental hospital, both outpatient and admitted patients combined, calculation of the rate of incidents by month showed that the highest average incidence occurred in October $(0.056 \%)$ and that the lowest was in August $(0.020 \%$, Table 2 and Figure 1$)$.

\section{Reported causes of adverse incidents}

Over one fifth $(n=63,22 \%)$ of all incidents that occurred at the hospital between 2005 and 2010 involved local anesthetic needles, making them the most commonly reported cause (Figure 2). Dental drill burs were the second most common cause of injury $(\mathrm{n}=51,17.8 \%)$, followed by dental probes $(\mathrm{n}=27,9.4 \%)$ and suture needles $(\mathrm{n}=16,5.6 \%)$. Splash incidents accounted for $19(6.6 \%)$ of the incidents, whilst less common causes involved elevators, scalpels, and scaler tips. The "other sharps" category encompasses those incidents that occurred rarely, and includes those involving matrix bands, tweezers, pliers, orthodontic wire, mirrors, midazolam ampoules, denture clasps, and even patients biting the clinician. The cause was unknown in $27(9.4 \%)$ of the incidents.

\section{Stage at which incident occurred}

Nearly three quarters of all the incidents $(n=208,72 \%)$ took place during treatment or whilst clearing away after the

Table I Rate of adverse incidents reported each year at one dental hospital, 2005-2009

\begin{tabular}{|c|c|c|c|c|c|c|c|}
\hline Year & $\begin{array}{l}\text { Outpatient } \\
\text { appointments (n) }\end{array}$ & $\begin{array}{l}\text { Admitted } \\
\text { surgical cases (n) }\end{array}$ & $\begin{array}{l}\text { Possible } \\
\text { interventions (n) }\end{array}$ & Incidents (n) & Incidence (\%) & Ratio & $\begin{array}{l}\text { Rate per } 10,000 \\
\text { case (outpatients } \\
\text { and day cases) }\end{array}$ \\
\hline 2005 & 80,153 & 6708 & 86,861 & 36 & 0.041 & $\mathrm{I}: 24$ & 4.1 \\
\hline 2006 & 119,363 & 7432 & 126,795 & 34 & 0.026 (lowest) & $\mathrm{I}: 37$ & 2.7 \\
\hline 2007 & I I 7,300 & 8604 & 125,904 & 61 & 0.048 (highest) & $|: 2|$ & 4.8 \\
\hline 2008 & 120,484 & 9805 & 130,289 & 51 & 0.039 & $\mathrm{I}: 26$ & 3.9 \\
\hline 2009 & I I3,822 & I I263 & 125,085 & 53 & 0.042 (highest) & $\mathrm{I}: 24$ & 4.2 \\
\hline 2010 & 134,625 & 10696 & $|45,32|$ & 52 & 0.035 & $\mathrm{I}: 28$ & 3.6 \\
\hline Total & 685,747 & 54,508 & 740,255 & 287 & 0.039 & $\mathrm{I}: 26$ & 3.9 \\
\hline
\end{tabular}


Table 2 Rate of adverse incidents reported each month over a 6-year period at one dental hospital

\begin{tabular}{llllllll}
\hline $\begin{array}{l}\text { Month (mean } \\
\text { over 6 years) }\end{array}$ & $\begin{array}{l}\text { Patient } \\
\text { appointments (n) }\end{array}$ & $\begin{array}{l}\text { Day surgery } \\
\text { patient } \\
\text { appointments (n) }\end{array}$ & $\begin{array}{l}\text { Possible } \\
\text { interventions (n) }\end{array}$ & $\begin{array}{l}\text { Incidents (n) } \\
\text { Incidence (\%) }\end{array}$ & $\begin{array}{l}\text { Ratio } \\
\text { Rate per } \\
\text { I 0,000 cases } \\
\text { (outpatients } \\
\text { and day cases) }\end{array}$ \\
\hline January & 53,148 & 4159 & 57,307 & 30 & 0.052 & $01: 19$ & 5.2 \\
February & 53,303 & 4058 & 57,361 & 20 & 0.035 & $01: 29$ & 3.5 \\
March & 57,288 & 4146 & 61,434 & 20 & 0.032 & $01: 31$ & 3.3 \\
April & 57,086 & 4119 & 61,205 & 28 & 0.046 & $01: 22$ & 4.6 \\
May & 56,268 & 4275 & 60,543 & 18 & 0.029 & $01: 34$ & 3 \\
June & 60,569 & 5175 & 65,744 & 16 & 0.024 & $01: 41$ & 2.4 \\
July & 60,037 & 5239 & 65,276 & 29 & 0.044 & $01: 22$ & 4.4 \\
August & 44,767 & 4682 & 49,449 & 10 & $0.020:($ lowest) & $01: 49$ & 2 \\
September & 62,140 & 4974 & 67,114 & 24 & 0.035 & $01: 28$ & 3.6 \\
October & 67,495 & 5428 & 72,923 & 41 & $0.056:$ (highest) & $01: 18$ & 5.6 \\
November & 66,162 & 4761 & 70,923 & 32 & 0.045 & $01: 22$ & 4.5 \\
December & 47,484 & 3492 & 50,976 & 19 & 0.037 & $01: 27$ & 3.7 \\
Total & 685,747 & 54508 & 740,255 & 287 & 0.038 & $01: 26$ & 3.9 \\
\hline
\end{tabular}

appointment. Only $3.5 \%(n=10)$ of incidents occurred before treatment commenced, and $3.8 \%(n=11)$ of the incidents were not clinically related. The stage at which the incident occurred was not specified in $20 \%(n=58)$ of the cases.

\section{Risk consequence score}

The "grade" column was completed for $100 \%$ of the incidents that occurred. Over half $(54 \%, n=129)$ of the incidents that occurred during the 6-year study period were graded as "green" (unlikely to occur again, very minor, or of no consequence) whilst $44 \%(n=154)$ were given a "yellow" grade, and only $2 \%(\mathrm{n}=5)$ were graded "amber". No incidents were graded "red".

\section{Actions taken}

From the data reported, it appears that an action was reported in $84 \%(n=242)$ of cases (Figure 3$)$. More than one action was reported in $69 \%(\mathrm{n}=168)$ of cases. The person involved in nearly half $(48 \%, \mathrm{n}=140)$ of the incidents bled and washed the injury, $27 \%(\mathrm{n}=80)$ applied a dressing/plaster,

\section{Average number of adverse incidents that occured each month}

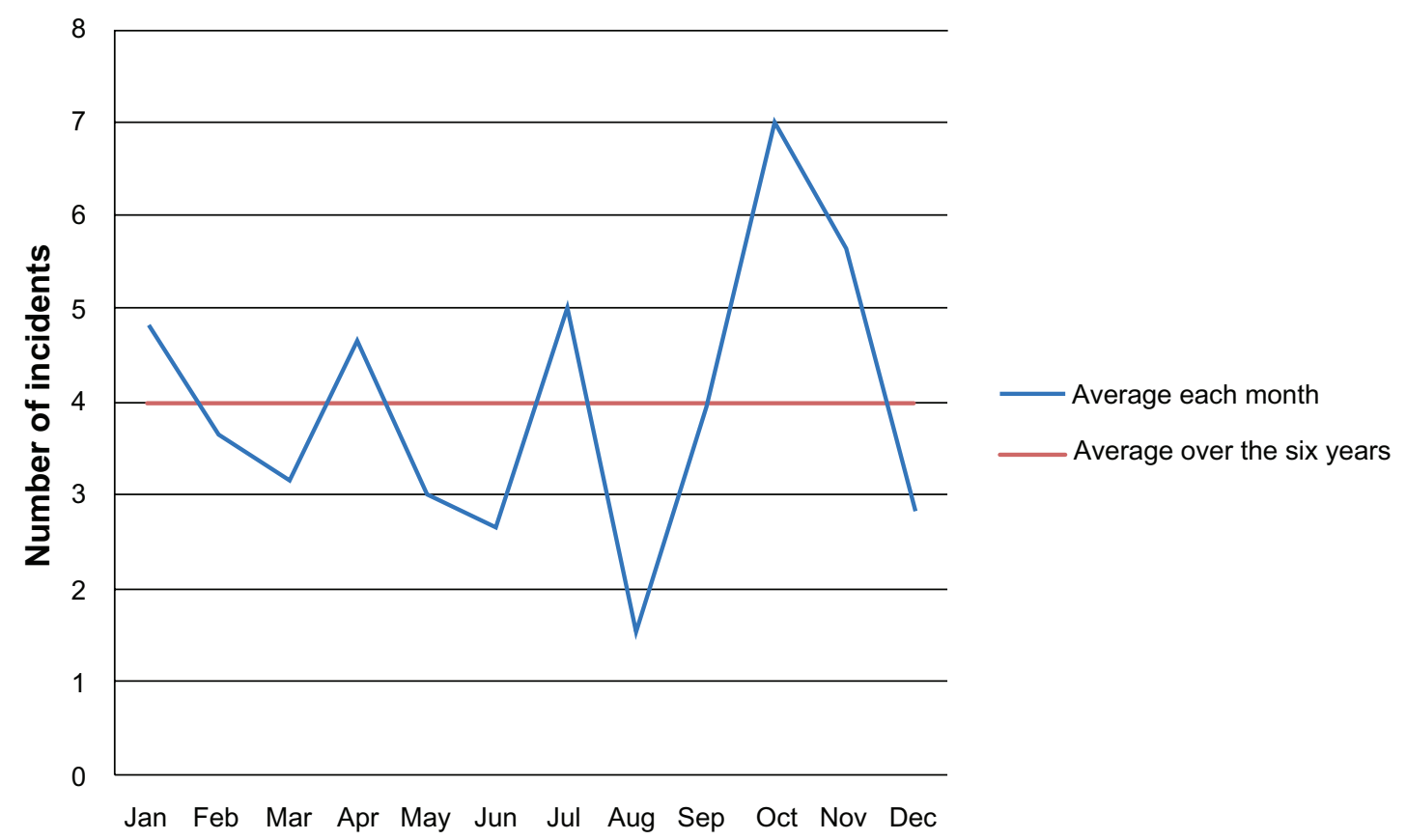

Figure I Average number of adverse incidents that occurred each month compared with the average that occurred over the 6-year period $(n=287)$. 


\section{The cause of adverse incidents occuring at a dental teaching hospital between 2005 and 2010}

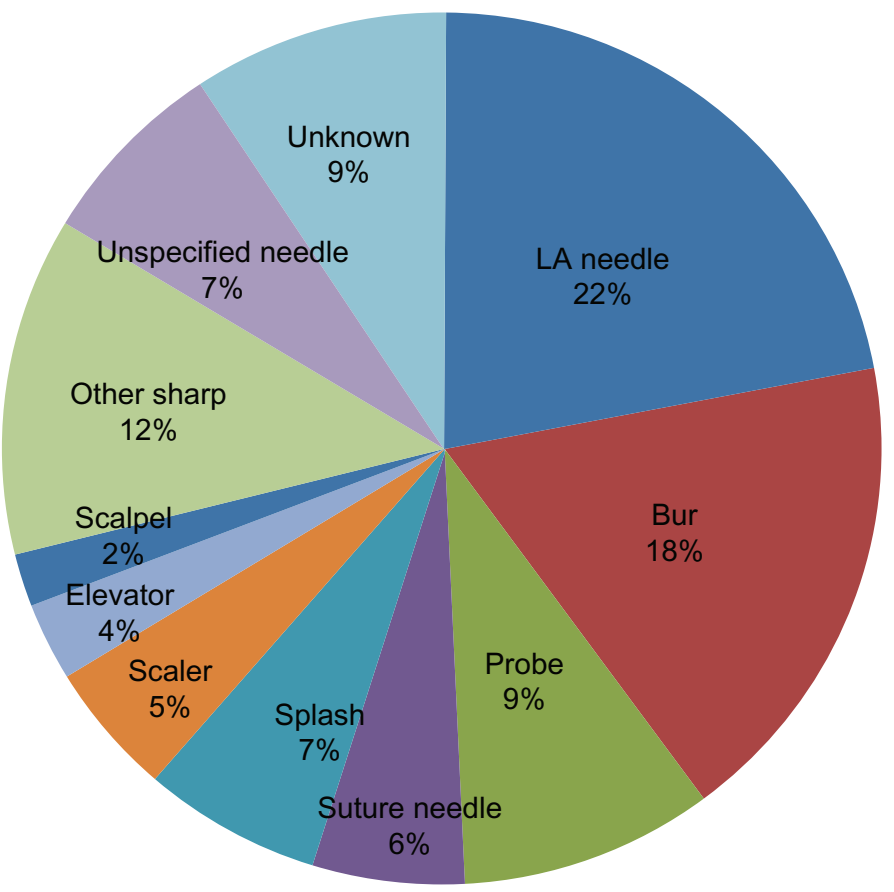

Figure 2 Reported cause of adverse incidents at the dental hospital $(n=287)$.

$32 \%(\mathrm{n}=93)$ attended the occupational health department for an assessment, and 3\% $(n=11)$ went straight to the accident and emergency department. A blood sample was taken from the patient on 26 occasions; this accounted for $9 \%$ of all incidents.

\section{Person involved}

The person involved in the incident was reported in 33\% $(n=94)$ of reported cases. Nine percent $(n=26)$ of those who identified themselves were dentists and $13 \%(n=37)$ were dental students. Dental nurses accounted for $6 \%$

\section{The actions taken following an adverse incident}

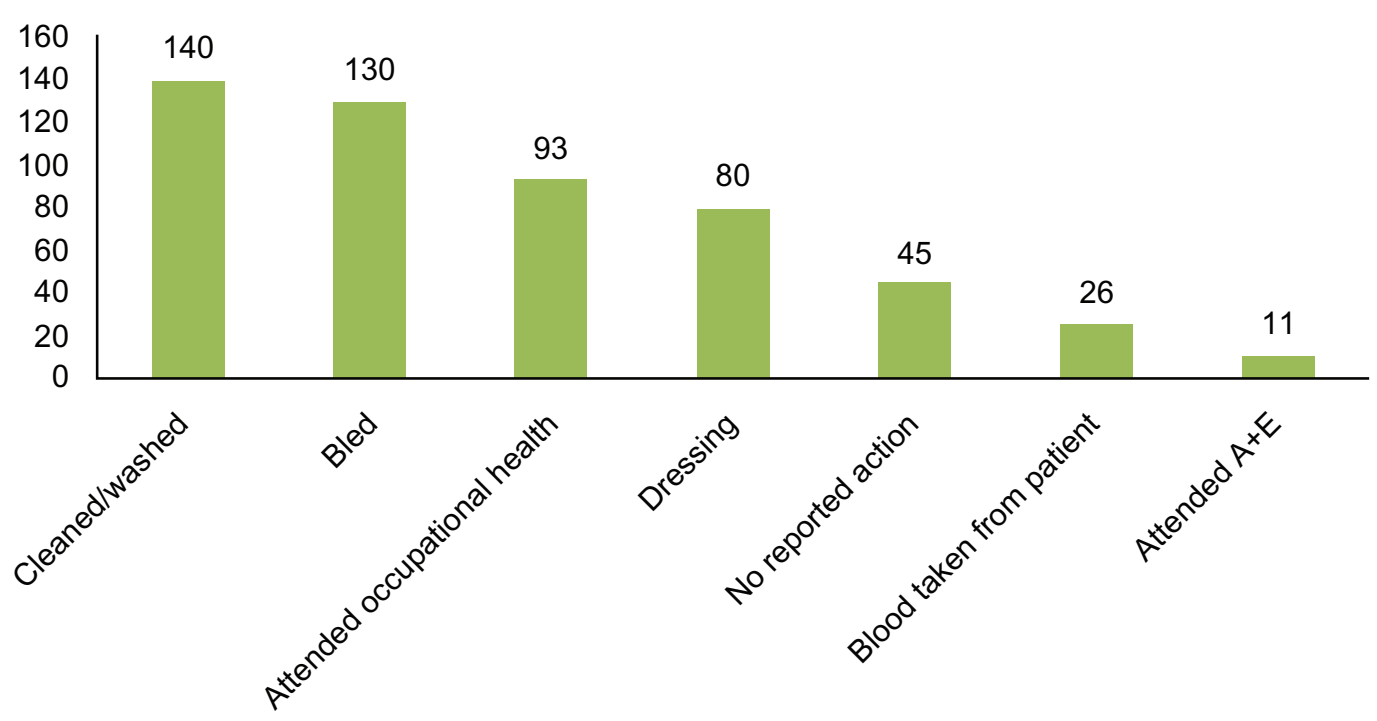

Figure 3 Reported actions taken following an adverse incident at one dental hospital, 2005-2009 ( $=242$ ).

Note: More than one action was taken following a number $(69 \%, n=168)$ of the adverse incidents which reported an outcome. 
$(\mathrm{n}=18)$, and student hygienists and therapists accounted for $2 \%(n=7)$.

\section{Location}

One fifth of the total number of incidents reported $(20.9 \%$, $\mathrm{n}=60$ ) took place at the "primary dental care" department whilst $(20.6 \%, \mathrm{n}=59)$ occurred at the "dental day case" department. Dental day case appointments accounted for $7.9 \%$ of total patient attendances at the hospital over the 6 -year period. A further $21.6 \%(n=62)$ were reported to have taken place at the "dental school" and reported incidents at individual departments, ie, acute dental care, orthodontic clinics, and pediatric clinics. Incidents at restorative clinics remained low throughout.

\section{Discussion}

This research suggests that adverse incidents are a feature of dental hospitals and highlights the common sources, all of which are central to the practice of dentistry. The importance of accurate and consistent reporting of data to ensure that these issues are monitored and inform action in support of reducing risks to staff, students, and patients is underlined. It also demonstrates the variation in reported incidence in relation to the academic year.

Recording and analyzing adverse incidents is essential to be able to monitor trends and identify areas where training and development may be required. This paper has highlighted that the consistent reporting and monitoring of events is imperative to re-enforce operator training. A Nigerian study reported that almost $72 \%$ of individuals who had been exposed to biological material failed to report the incident. ${ }^{7}$ There is also evidence from a dental school in Brazil that nonreporting of occupational accidents was related to the fact that students considered the exposure to be of minor or low risk or considered the protocol adopted by the institution to be inadequate. ${ }^{8}$ Therefore, we must accept that reported body fluid exposure incidents may only be the tip of the iceberg in dental schools as well as within the NHS generally. ${ }^{9}$ It may also be assumed that different staff reporting the incident may perceive varying degrees of detail to be satisfactory, thus highlighting the need for more thorough record-keeping criteria. It should also be noted that the data available on Datixweb do not indicate whether the incident has been followed up by the occupational health department. In principle, clinical workers at the hospital have good access to occupational health services, but communication between departments could be strengthened further. The importance of data recording to assist with learning from incidents and preventing them in future cannot be emphasized too much, and should be part of staff induction training at the hospital.

Trends are present in the data suggesting that a student presence at the dental hospital influenced a bias towards a higher incidence, with peaks apparent during term time, particularly the autumn. This could not be validated from the recorded data because the person involved in the incident was not specified in $66 \%(n=191)$ of cases. Nonetheless, the relationship with volume strongly suggests that staff working during the month of August are more experienced, and indeed there are no undergraduate or dental care professional students at that time, so this hypothesis may be justified by the average incident rate during the month of August, being 2.2 per 10,000 compared with the average incident rate of 6.1 per 10,000 during October. The average incident rate over the six years was 3.9 per 10,000 visits, which is of a similar order of magnitude to a US study of dental schools across the US which reported an average exposure rate of 4.0 per 10,000 patient visits. Past research supports the view that teaching environments have higher incidences of occupational exposures than nonteaching environments. , $^{3,8,10-12}$

The peak in 2007 could be associated with additional students providing care on site, following an expansion of student numbers. Past research highlights the importance of introducing safe practices and guidance. ${ }^{12} \mathrm{~A}$ drive to reduce the rate of incidents led to the improvement of induction and training for year 3 students in 2008. A " $100 \%$ no resheathing policy" was introduced in August 2008 in line with recommendations from the UK Department of Health, whilst instruction was given in safe disposal of dental needles in sharps bins following single use, which consequently may have been responsible for the reduction and plateau of incidents. This issue is particularly important in dental teaching hospitals where there are responsibilities for staff, students, and patients.

The occurrence of an adverse incident was most frequently reported in association with the administration of local anesthetic and a dental bur, followed by incidents involving probes and suture needles. In reviewing reports from various dental schools, it appears that the same trend is common, ${ }^{10,13}$ and that junior students appear to be more at risk than students in final year. ${ }^{11}$ A policy at the trust does indicate that the clinician should dispose of his/her own sharp instruments immediately after surgery in the sharps containers which have been installed in each cubicle/operating room. The figures suggest that further training is needed in these areas, with particular regard to the administration of anesthetic. Unfortunately, lack of detail about who was 
involved in each incident makes it difficult to specify who should be targeted for further training.

These study data include the reported consequences of the incident. Over half of the incidents that occurred were reported to have minor consequences. Forty-four percent had no recorded consequence and $2 \%$ of the incidents had moderate consequences. This does not reflect the availability of support in occupational health services to support health care personnel in this hospital, but may be a reflection of the low severity of the incidents. Nonetheless, this analysis highlights the need for incidents to be taken seriously, fully recorded, and followed up. Further research in this area should involve monitoring and reporting of blood samples of staff and patients.

All incidents that occurred during the 6-year period were graded according to their risk at the time of reporting; however, it became apparent during examination of the data that the "descriptions" of each incident varied significantly in detail due to reporter variation. This made categorization challenging, so it could be proposed that training for incident reporting should be put into practice. A more uniform coding system would make future analysis more efficient.

The clinical workforce at the dental hospital has full access to the occupational health department at all times, and it was reported that over a third of those suffering an incident attended the department. Occupational health records cannot be accessed via the Datixweb system, which is a clear barrier to consistent follow-up.

\section{Conclusion}

This research suggests that adverse incidents are a feature of dental hospitals, highlighting the importance of accurate and consistent reporting of data to ensure that these issues are monitored and addressed in support of staff, students and patients. Aspects of clinical practice and groups of health care workers that would benefit from action to protect staff and indirectly the health of their patients are identified.

\section{Acknowledgments}

The research team would like to acknowledge Davisha Humzah, hospital manager, and Mustafa Al-Haboubi, clinical researcher in dental public health, for their assistance with data management, and Professor Stephen Dunne for his support. This study was facilitated by King's College London and King's College Hospital, and conducted within existing staff resources.

\section{Disclosure}

The authors report no conflicts of interest in this work.

\section{References}

1. Department of Health. An Organisation with a Memory. London, UK: Department of Health; 2000.

2. World Health Alliance for Patient Safety. WHO Draft Guidelines for Adverse Event Reporting and Learning Systems. Geneva, Switzerland: World Health Organization; 2005.

3. Younai F, Murphy D, Kotelchuck D. Occupational exposures to blood in a dental teaching environment: results of a ten-year surveillance study. J Dent Educ. 2001;65(5):436-448.

4. Department of Health. Health Clearance for Tuberculosis, Hepatitis B, Hepatitis Cand HIV: New Healthcare Workers. London, UK: Department of Health; 2007.

5. Expert Advisory Group on AIDS and the Advisory Group on Hepatitis. Guidance for Clinical Health Care Workers: Protection Against Infection with Blood-Borne Viruses. London, UK: Her Majesty's Stationery Office; 1998.

6. King's College Hospital NHS Foundation Trust. Policy for the Management, Reporting and Investigation of Adverse Incidents (Including Serious Adverse Incidents). London, UK: King's College Hospital NHS Foundation Trust; 2010.

7. Sofola OO, Folayan MO, Denloye OO, Okeigbemen SA. Occupational exposure to bloodborne pathogens and management of exposure incidents in Nigerian dental schools. J Dent Educ. 2007;71(6): 832-837.

8. Machado-Carvalhais HP, Martins TCPM, Ramos-Jorge ML, et al. Management of occupational bloodborne exposure in a dental teaching environment. J Dent Educ. 2007;71(10):1348-1355.

9. Elmiyeh B, Whitaker IS, James MJ, et al. Needle-stick injuries in the National Health Service: a culture of silence. J R Soc Med. 2004;97(7): 326-327.

10. Kotelchuck D, Murphy D, Younai F. Impact of underreporting on the management of occupational bloodborne exposures in a dental teaching environment. J Dent Educ. 2004;68(6):614-622.

11. Stewardson DA, Palenik CJ, McHugh ES, Burke FJT. Occupational exposures occurring in students in a UK dental school. Eur J Dent Educ. 2002;6(3):104-113.

12. Atenstaed RL, Payne S, Roberts RJ, et al. Needle-stick injuries in primary care in Wales. J Public Health (Oxf). 2007;29(4):434-440.

13. Machado-Carvalhais HP, Ramos-Jorge ML, Auad SM, et al. Occupational exposure to potentially infectious biological material in a dental teaching environment. J Dent Educ. 2008;72(10):1201-1208.
Infection and Drug Resistance

\section{Publish your work in this journal}

Infection and Drug Resistance is an international, peer-reviewed openaccess journal that focuses on the optimal treatment of infection (bacterial, fungal and viral) and the development and institution of preventive strategies to minimize the development and spread of resistance. The journal is specifically concerned with the epidemiology of antibiotic

\section{Dovepress}

resistance and the mechanisms of resistance development and diffusion in both hospitals and the community. The manuscript management system is completely online and includes a very quick and fair peerreview system, which is all easy to use. Visit http://www.dovepress.com/ testimonials.php to read real quotes from published authors. 